\title{
Formal and Informal Institutions in Governance Networks: Managing Diabetes in Australia and India
}

\section{Crawford School Working Paper 1601 October 2016}

\author{
Lhawang Ugyel
}

\section{Abstract}

Networks are increasingly being used a models to capture elements of governing neglected by the bureaucracy and market models in public administration and management. However, extant literature on networks uses the concept in a narrow manner, and tends to mostly focus on formal networks. Informal networks have not received adequate attention. In this paper I argue that it is equally important to focus on informal networks, in addition to the formal networks, in public administration and management. Based on a comparative case study of diabetes care in Australia and India, this paper develops a typology of diabetes network in these two countries with the type of network (that is, formal and informal networks) on one side of the matrix and the type of health professional (that is, professional and non-professional) on the other side. Mapping the prevailing diabetes care of the two countries onto the matrix reveals that diabetes care in Australia relies mostly in the formal network quadrants, that is, health professionals and voluntary and community groups. And diabetes care in India relies on the informal network quadrants, that is, non-health professionals and personal communities. While the paper discusses some of the reasons why each of these countries rely on a particular type of network for diabetes care, the main finding of the paper is that infusing aspects of the formal and informal networks results in improved health outcomes for people with diabetes as well as reducing the increasing costs of diabetes care. The field of public administration and management can certainly draw on the experiences of diabetes care by using both formal and informal networks to improve outcomes as well as to minimize expenses. 


\section{Suggested Citation:}

Ugyel, L. (2016), Formal and Informal Institutions in Governance Networks: Managing Diabetes in Australia and India, Crawford School working paper 1601. Crawford School of Public Policy, The Australian National University.

\section{Address for Correspondence:}

Lhawang Ugyel

Lecturer

Development Policy Centre

Crawford School of Public Policy

Australian National University

ACT 2601

Australia

Email: Lhawang.ugyel@anu.edu.au

Crawford School of Public Policy

College of Asia and the Pacific

The Australian National University

Canberra ACT 0200 Australia

www.anu.edu.au

The Crawford School of Public Policy is the Australian National University's public policy school, serving and influencing Australia, Asia and the Pacific through advanced policy research, graduate and executive education, and policy impact. 


\title{
FORMALAND INFORMAL INSTITUTIONS IN GOVERNANCE NETWORKS: MANAGING DIABETES IN AUSTRALIA AND INDIA
}

\begin{abstract}
Networks are increasingly being used a models to capture elements of governing neglected by the bureaucracy and market models in public administration and management. However, extant literature on networks uses the concept in a narrow manner, and tends to mostly focus on formal networks. Informal networks have not received adequate attention. In this paper I argue that it is equally important to focus on informal networks, in addition to the formal networks, in public administration and management.
\end{abstract}

Based on a comparative case study of diabetes care in Australia and India, this paper develops a typology of diabetes network in these two countries with the type of network (that is, formal and informal networks) on one side of the matrix and the type of health professional (that is, professional and non-professional) on the other side. Mapping the prevailing diabetes care of the two countries onto the matrix reveals that diabetes care in Australia relies mostly in the formal network quadrants, that is, health professionals and voluntary and community groups. And diabetes care in India relies on the informal network quadrants, that is, non-health professionals and personal communities.

While the paper discusses some of the reasons why each of these countries rely on a particular type of network for diabetes care, the main finding of the paper is that infusing aspects of the formal and informal networks results in improved health outcomes for people with diabetes as well as reducing the increasing costs of diabetes care. The field of public administration and management can certainly draw on the experiences of diabetes care by using both formal and informal networks to improve outcomes as well as to minimize expenses.

\section{Introduction}

The network model has emerged in the field of public administration to capture elements of governing neglected by the bureaucracy and market models. The growth of the network model in public administration and management can be attributed to various factors. One of the main reasons is the increase in the control of policy by an 'amorphous collections of actors' that are not formal policy making institutions in government (Peters and Pierre 1998, 225). Another reason is the blurring boundaries between firms, non-profits and government agencies (Considine and Lewis 2003). A third plausible factor is the requirement of the state to steer society in new ways through the development of complex networks and the rise of more bottom-up approaches to decision making (Stoker 2006). Unlike bureaucracy, networks are not linked in single vertical structures and involve horizontal multi-sectoral collaboration. And unlike the market, networks work together because of shared interest in a particular outcome where contractual arrangements are relational and open-ended rather than a specified classic market contract. Networks, according to O'Toole (1997, 45), excludes 'mere formal hierarchies and perfect markets, but it includes a very wide range of structures in between'. In other words, a public management network includes governmental and nongovernmental agencies involved in public policy making, and that such network structures stress the importance of both formal and informal interactions between participants 
in the policy process (Rhodes 2008; Blanco et al. 2011; McGuire and Agranoff 2011). It is mostly the formal interactions and legal structures that have been the focus when examining public management networks. For instance, Ansell and Gash $(2007,546)$ use the criteria of 'formal collaboration' to distinguish collaborative governance from more casual and conventional forms of agency-interest group interaction. Similarly, Provan and Kenis (2008, 231) use the term network 'narrowly' focusing on groups of three or more legally autonomous organizations that work together. There is a dearth of studies that focus on "informal networks" in public management. Part of the problem is because of the difficulty, in general, related to the concept of networks itself. As Pollitt and Hupe $(2011,652)$ contend, it is difficult to count the total number of networks and the concept of network, although attractive, can be quite broad and abstract.

This paper takes a broader perspective towards networks based on the definition provided by Emerson et al. (2012, 3), which include:

Partnerships among the state, the private sector, civil society, and the community, as well as joined-up government and hybrid arrangements such as public-private and private-social partnerships and co-management regimes ... [And] the myriad of community-based collaboratives involved in collective resource management (that often invite the participation of public agencies), as well as intergovernmental collaborative structures ... among other types of collaborative arrangements initiated in the private or civic sectors.

In doing so, this paper argues that although the definition of networks include both "formal" and "informal" networks, however, most network studies are focused on "formal" networks. There is also this need to focus on informal networks because of the important role they play in certain countries, particularly developing countries where there is a lack of presence of formal networks. Another advantage of including informal networks is that costs are often associated in maintaining formal networks resulting in increased pressure on service delivery mechanisms and provisions. Various studies, Klijn and Koppenjan (2012) contend, illustrate that network involvement results in positive outcomes and better performance. To highlight the role of formal and informal networks in service delivery, this paper presents a comparative case study of diabetes care in India and Australia. The paper discusses the networks that operate in diabetes care and examines the role of networks, particularly informal networks such as families and communities, in countries where formal networks are weak. The significance of the role of networks is acknowledged by Isett and Provan (2005), who argue that as policy makers continue to encourage the formation of service provision networks, in areas such as health, among private and non-profit organizations, it is important to understand how networks work.

\section{Public management network}

With the increasing use of the concept of "network", there is also a tendency to misunderstand, and oftentimes, misuse the concept. According to Blanco et al. $(2011,297)$, in the trend to increasingly use network as a response to complex problems there is a tendency to 'conflate and confuse' the two terms - policy network and governance network - and are 'often used interchangeably'. These two terms, in fact, are two of the three major streams of network research that have contributed important insights and frameworks to the disciplines in which they are grounded (Berry et al. 2004). The third one, social network analysis, is 
from the field of sociology and its origins can be traced back to the 1930s. Based on sociometric studies, social network analysis represents groups as collection of points connected by lines to draw relationship networks among people and to identify patterns of interaction, cliques and small group dynamics (Berry et al. 2004), and maps interactions and identifies the structural features that emerge in networks (Klijn and Koppenjan 2012). Policy network derives its theoretical underpinnings from the field of political science and has been active since the early 1970s. Networks in political science have been important to assess how networks affect collective action and policy outcomes, and have contributed significantly to the work on agenda setting and policy development, and the role of policy networks and communication lines among association/interest group members, policy specialists and elected officials and their staff (Berry et al. 2004). Governance networks is from the field of public administration and management, which is slightly more recent and dates back to the mid-1980s. It grew primarily out of research in intergovernmental relations and is studied in public management to understand: whether or not networks exist and how they function, how people function in networks as managers, and what impacts networks have on policy processes, outcomes and values. According to McGuire and Agranoff $(2011,266)$, networks in public administration and management form a central part of governance network focusing directly on managerial arrangement and behaviour. Duit and Galaz $(2008,324)$ also acknowledge that the network based governance model promotes 'high learning capacity and adaptability in multilevel governance systems' because of the flexibility created by informal cooperative arrangements in combination with higher levels of actor diversity. In many ways, governance network are effective in tackling wicked problems, that is, in situations where there are no obvious solutions and that cut across hierarchy and authority structures within and between organizations and across policy domains, political and administrative jurisdictions, and political group interests (Weber and Khademian 2007; Ferlie et al. 2011). In such situations, governance networks enable working across boundaries and engaging citizens and stakeholders in co-producing policy making and implementation.

On the one hand, the network approach is not without its problems (Pollitt and Hupe 2011; McGuire and Agranoff 2011). As Pollitt and Hupe (2011, 651) point out although reflective of recent trends, networks sit 'uneasily with a number of traditional liberal democratic norms' and that the explanatory value of network approach has been criticised. On the other hand, Berry et al. $(2004,504)$ argue that there has been relatively little 'cross-fertilization' across the research traditions with a lack of interdisciplinary dialogue that leads to confusion of networks. Despite the distinctiveness of the policy network and governance network approaches, Blanco et al. (2011) conclude that both remain relevant and that they are important theoretical elements of governance and policy making. Similarly, Klijn and Koppenjan (2012) observe that convergence has occurred among the research traditions that use a network approach with increasing cross-citations and the use of concepts derived from the different traditions have increased. While this paper focuses mainly on the concept of network from a governance network perspective, it also uses concepts from both the policy network and social analysis network. However, as a starting point, this paper examines some of the main features of governance network.

Governance network share horizontal relationships, across institutions and sectors. According to Osborne $(2006,384)$, governance network posits both a 'plural state', where multiple interdependent actors contribute to the delivery of public services and a 'pluralist state', where multiple processes inform the policy making system, and as a result of these two forms of plurality its focus is very much upon inter-organizational relationships and the governance of processes. Networks can be distinguished by their horizontal scope and non-hiearchical way 
of perceiving the policymaking process and a horizontal scope (Carlsson 2000). Networks can also take many different forms, which according to Sorensen and Torfing $(2005,197)$ is an attestation to the relevance of the concept of networks to describe contemporary forms of societal governance, and they can be either 'self-grown' or 'initiated from above' and they might be dominated by 'loose and informal contacts' or take the form of 'tight and formalized networks'. Governance networks involve complex interactions between independent actors with divergent interests and that networks cut through different layers of government and connect governmental actors with a wide range of private and semi-private actors (Klijn and Koppenjan 2012). Another feature of governance network is that interactions are based on cooperation. Networks involves the collaboration of a wide range of participants as legitimate members of the decision-making process (Stoker 2006). According to Brinkerhoff $(2002,20-21)$, building on democratic values, such as participation and empowerment, partnerships among diverse actors is the 'most ethically and appropriate approach to sustainable development and service delivery'. The cooperative interactions in a network are executed through structures of 'interagency collaboration' (O'Toole 1997, 46), which recognizes the importance of formal and informal rules and protocols, institutional design, and other structural dimensions to on-going collaboration (Emerson et al. 2012, 14). According to Isett and Provan (2005, 150-1), unlike a market setting where dyadic relationships where partners come together to seek gains in productivity from one another, in a network setting partners come together in a 'facilitated environment where a governance structure is often overlaid in partner organizations'. Furthermore, network managers also try to build trust among the participating parties (O'Toole 1997). The third feature of networks is that the various actors and partners are relatively independent of central state and authority. Networks represent a decentralized concept of social organization and governance (Carlsson 2000). According to (Sorensen and Torfing 2005, 197), networks operate in a 'relatively stable horizontal articulation of interdependent, but operationally autonomous actors' that is 'self-regulating within limits set by external agencies'. According to Weber and Khademian $(2007,334)$ networks are 'defined by the enduring exchange relations established between organizations, individuals and groups' and their relationships may be simple arrangements between two government agencies or a complex combination of organizations, groups and individuals from a variety of sectors. Members of the network govern themselves 'with no separate and unique governance entity' and this form of governance can be 'accomplished either formally' or 'more informally through the ongoing but typically uncoordinated efforts of those who have a stake in network success (Provan and Kenis 2008, 234).

\section{Networks in diabetes care}

Diabetes is a serious chronic disease. It is a cluster of metabolic conditions where the body is unable to automatically regulate blood glucose levels due to a relative or absolute lack of the hormone insulin. The three major classifications of diabetes are type 1 diabetes, type 2 diabetes and Gestational Diabetes Mellitus (GDM). Type 1 diabetes is an autoimmune system disease marked by absolute insulin deficiency and the need for lifelong insulin replacement therapy. Type 2 diabetes is caused by relative insulin deficiency associated with insulin resistance that can often be delayed and sometimes prevented with appropriate life style changes. GDM is diabetes that occurs in pregnancy, related to insulin resistance and is associated with an increased risk of developing type 2 diabetes later in life. This paper will mainly focus on networks in the care of people with type 2 diabetes. Since diabetes can only be managed but cannot yet be cured, people with diabetes require long-term care by health professionals, non-health professionals and themselves. According to Schiotz et al. (2011, 654) people with diabetes typically have only a few clinic visits each year, totalling less than 
2 hours of formal diabetes care, and people with diabetes manage the 'overwhelming majority of their diabetes-related needs' on their own. Furthermore, they add that several studies have shown that a greater level of social support correlates with better diabetes selfmanagement, which also includes formal healthcare providers and informal social network members. According to Provan and Kenis $(2008,234)$, in 'health and human services, shared governance networks are common because networks are considered to be an important way of building community capacity' and 'only by having all network members participate, on an equal basis, will participants be committed to the goals of the network'.

Using a social-network approach, Rogers et al. (2011) provide a useful overview of the systems of support in long-term-condition management, of which diabetes is one. While the management of the disease is the responsibility of the health professionals, a social network approach also shifts the focus of the management to the person with the long-term condition, members of the personal communities, support and community groups and non-health professionals. These four categories form, what Rogers et al. $(2011,2)$ identify as the 'systems of support' for people with long-term care. Based on this system of care, this paper has adapted the framework to form a typology that identifies the various types of support provided in diabetes care. The typology identifies four types of support systems, which can be considered ideal types, based on two dimensions. The first dimension is the type of network, that is, formal and informal networks; and the second dimension is the type of health personnel, that is, professional and non-professional. Four basic types of diabetes care providers can be identified (refer to Table 1). The formal - professional quadrant are the health professionals and include people such as general physicians, nurses, allied health professionals and specialists. The informal - professional quadrant are the non-health professionals and include people such as traditional healers, spiritualists and herbalists. The formal - non-professional quadrant are the voluntary and community groups and include support groups, discussion groups and other social groups. The informal - non-professional quadrant are the personal communities and include spouse and partner, family, friends, relatives, neighbours and community.

Table 1: Typology of Diabetes Network

\section{Network}

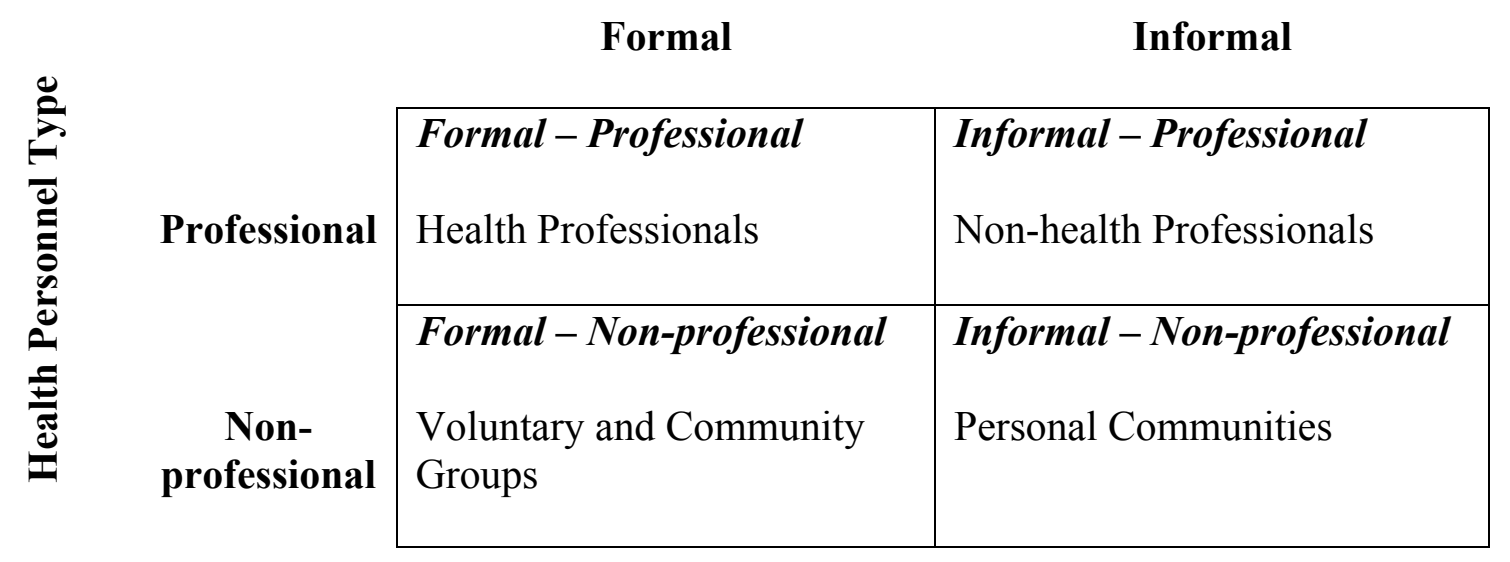




\section{Formal and informal networks in diabetes care}

In both Australia and India, diabetes has been identified as one of the major disease affecting a wider population. In Australia, there is an increasing incidence and prevalence of diabetes, in particular, type 2 diabetes. It is estimated that almost 1 million Australians have been diagnosed with diabetes, and the AusDiab Study 2005 reveals that the diabetes prevalence is 7.4 percent, one of the highest in the Western nations. Almost 4 percent of Australians were diagnosed with diabetes in 2007-08, which had doubled since 1989-90 (AIHW 2009). With the subsequent increase in the number of people with diabetes, there has been a rising cost of public health expenditure. In 2003, diabetes and its complications accounted for over 8 percent of the total disease burden (AIHW 2009). In a report by the Australian government (Commonwealth 2010), it predicts that the burden of chronic disease is projected to dramatically increase and the spending on type 2 diabetes is projected to increase by as much as 520 percent between the period 2002-03 and 2032-33.

Similarly, India is among the top three countries with the highest number of people with diabetes and is on verge on being the 'diabetes capital of the world' (Nachman et al. 2010, 2; Balagopal et al. 2008). In India, there are 62.4 million people reported to be suffering from diabetes, and that according to estimates by the International Diabetes Federations, over 101 million people will have diabetes in India by the year 2030 (Joshi et al. 2013). According to Joshi et al. (2008) the 'genetic predisposition combined with lifestyle changes associated with urbanization and globalization contribute to the rapid rise of diabetes in India' and that 'type 2 diabetes in the Indian population appears to occur at least a decade earlier' compared to Western nations. In addition to the impact on the 'productivity of the youth' (Joshi et al. 2008 ) and approximately $70 \%$ of India's population living in rural areas in resource poor setting where there is an increasing prevalence and chronic nature of diabetes (Balagopal et al. 2008), the economic burden of diabetes can be huge. And the economic burden of diabetes for India, which has almost 25 percent of its population under poverty, will have a major impact on diabetes care (Kalra et al. 2013; Ramachandran et al. 2013).

\section{Formal diabetes care networks in Australia}

Diabetes care in Australia is provided mainly by the formal networks. The first category of care providers are by health professionals who are situated within the formal network. In Australia, general practitioners (GPs) are often the first point of contact for people diagnosed with diabetes. Although the roles of GPs are really important in diabetes care, particularly in implementation of the components of the diabetes cycle of care (Saunders et al. 2008); numerous studies (for example, Proudfoot et al. 2007, Infante et al. 2004, Aylen et al. 2006, Harris 2008, Taggart et al. 2009) show that GPs are only able to provide sub-optimal care to people with diabetes. The main barriers in the provision of effective care in the general practice are because of the limited organizational capacity to provide structured care (Harris 2008; Proudfoot et al. 2007), lack of time and work pressure (Harris 2008; Aylen et al. 2006), and a lack of knowledge of what is available in terms of diabetes education services (Aylen et al. 2006). Referrals are made by the GP to the relevant levels of care depending on the type of diabetes. Normally and when available, GPs refer persons with type 1 diabetes directly to tertiary care, either to an endocrinologist or for hospitalisations. For type 2 diabetes, the referral patterns vary. At the basic level, that is, the primary level of care, persons with type 2 diabetes are managed by GPs themselves and/or a practice nurse. The person's needs at this level are fairly simple at the diagnosis stage, requiring a complications screening and basic 
information about weight loss, diet, exercise and smoking. The second level of care is often provided by a diabetes educator and a multi-disciplinary team that comprises of the dietitian, ophthalmologist or optometrist and podiatrist. Some of the other allied health professionals who may be consulted by the patients depending on the needs are exercise professional, oral health professional and pharmacists. This allows people with type 2 diabetes access to a range of services, which includes the development of personal care plans, setting targets during the initial years and in the following years, providing medications, undertaking regular complications screening and initiating intensified diabetes treatment options. Once the disease progresses, the care may have to be provided by tertiary services. Management of longstanding type 2 diabetes is frequently more complex and often requires insulin initiation, insulin and glycaemic stabilisation, prevention strategies for acute diabetes complications and management of advanced chronic diabetes complications.

The second category of diabetes care providers are the formal networks but comprise of nonprofessionals. One such example is Diabetes Australia, a not-for-profit organization. According to their website (www.diabetesaustralia.com.au), Diabetes Australia was established in 1984 as the national body for people affected by diabetes with the objective to reduce the impact of diabetes. Working together with diabetes health professionals and educators, researchers and healthcare providers, Diabetes Australia provides practical assistance, information and subsidised products to Australians diagnosed with diabetes. Similarly, the Australian Diabetes Educators Association (ADEA), a company limited by guarantee (a form of not-for-profit organisation) formed in 1981, actively promotes best practice diabetes education to ensure optimal health and well-being for all people affected by, and at risk of, diabetes. By providing a credentialing program to its members, who are mostly diabetes educators in Australia, the ADEA provides a national voice on matters of diabetes education and care (ADEA 2015).

\section{Informal diabetes care networks in India}

In general, health care in India is provided by a variety of players, both governmental and non-governmental. The governmental system comprises of a network of sub-centres, primary health centres and community health centres in rural areas, district hospitals, tertiary care hospitals and medical colleges in the cities. The focus, however, continues to be on primary and basic health services, and the need for long-term care, such as diabetes, is a relatively new health concern with personnel and infrastructure inadequate to cater to diabetes care (Venkataraman et al. 2009). Because of the constraints of professionals and capacity, Venkataraman et al. (2009), warn that the increasing load of diabetes is a major concern. Another reason why diabetes is a major disease in India is because awareness about noncommunicable diseases, such as diabetes, is 'not recognized by the public, especially those who have low education levels' (Ramachandran et al. 2013, 188). In addition, according to Ramchandran et al. (2013, 188), 'wide disparities in socioeconomic level, educational background and non-availability of diabetes care are some of the major hurdles in the management of diabetes or any other chronic diseases in India'.

Some of the key reasons why diabetes poses to be a major problem in India is because of problems that plague the formal-professional network. In a study conducted by Hasan et al. (2011) they point to various shortcomings with the health professionals related to diabetes care. Firstly, shortages in physicians and nurses adversely affect appropriate and effective diabetes care, and this was further constrained by the shortage of institutions as well as shortage of faculty at the institutions. Ramachandran et al. $(2013,189)$ also acknowledge that 
patient education and empowerment are key steps in assuring good glycemic control', however, the 'facility and adequate manpower for these are not available even in major cities'. Secondly, medical education in India does not emphasize the concept of a team approach, involving shared responsibilities between the physicians, nurses and allied health workers leading to sub-optimal diabetes care. Joshi et al. $(2008,141)$ note that 'the number of doctors and nurses trained to provide diabetes care does not match the huge number of patients' including a 'shortage of trained personnel to create awareness and educate' people on diabetes. Thirdly, there are no incentives for updating clinical skills' resulting in 'huge variations in the quality and type of care' with most qualified practitioners located in urban areas. And according to Chow et al. $(2006,1717)$, although very high levels of diabetes have been reported in urban areas, rural India, where a majority of the population reside 'may soon experience the same epidemic of diabetes'. Joshi et al. (2013) acknowledge that diabetes educators, whose role is a vital link between the physicians and patient, are currently absent in India, and that the need to train qualified diabetes educators to cater to the increasing number of people with diabetes is obvious.

There have been some attempts made by the governments and non-government organizations that are situated within the formal - non-professional networks such as Diabetics India (www.dairaheja.org) and the Association of Diabetes Educators (www.diabeteseducatorsindia.com) to create awareness through health camps and other awareness campaigns. However, Ramachandran et al. (2013) contend that the awareness is still low, particularly in rural areas. And the impacts of various diabetes programs are minimal, as Kalra et al. (2013) point out that people with diabetes in India have 'one of the lowest levels of psychological wellbeing on the World Health Organization-5 (WHO-5) Well-being Index' and exhibited a higher perception of burden of social and personal distress associated with diabetes. In general, knowledge and awareness levels of Indians regarding diabetes is low and they have poor understanding of the relationship between control and complications (Joshi et al. 2013; Joshi et al. 2008). Broad factors such as socio-economic, educational, cultural, language barriers, poverty, and at the micro level lack of accessibility to health services and inadequate follow-up were some of the challenges in implementing effective diabetes programs.

Given the acute shortcoming of professionals on one hand, and on the other hand the cultural setting in India requires an informal network to provide diabetes care, particularly on the education aspects. In one of the few but insightful studies conducted on the role of informal networks in India, Kalra et al. (2013) reported that less than one-third of the doctors reported using clinical guidelines in their practice and that the biggest hindrances to the use of these guidelines are poor knowledge and the non-applicability of international guidelines in the Indian context. They note that the linguistic, social, cultural, economic and ethnic heterogeneity of the Indian population makes the Indian diabetes situation unique. Coupled with limited economic resources and human resources for diabetes care in India, Kalra et al. (2013) contend that India's strong sociocultural ethos can be utilized to manage diabetes more efficiently at the individual, family and community level. They point to several studies from India that demonstrates the importance of family structure in the management of diabetes and that cost-effective focus for overall diabetes care can be placed on the nuclear family as a unit, and that social bonds, especially family bonds, are known to influence outcomes of diabetes management, which holds the key to avoiding negative progression of the disease. 


\section{Importance of informal networks in public management}

From what we saw in the earlier section (particularly based on Figure 1), diabetes care is mostly within the quadrants on formal institutions in Australia and for India, it is mostly within the informal institutions quadrants. In India's case, India does not have the formal institutions, and there is a dearth of health professionals. There is definitely the need to build their capacity in the long-term but in the short-term, there is also this need to make use of existing informal institutions till such a time. The key really is to determine how to better utilize families and communities to manage people with diabetes. Similarly, in the case of Australia, while the formal institutions to manage people with diabetes are in place there is this need to complement the formal institutions with informal institutions. Particularly with the increasing numbers of people with diabetes in Australia, it will be a challenge for the professional service providers to take on additional responsibilities. In addition there is this issue of increasing costs of managing people with diabetes, which is also relevant for the case of India. There is this need to off-load the pressure of the formal institutions and get the actors in the informal institutions involved. Therefore, there is this realization that the informal institutions in the management of diabetes is important.

Focusing on the importance of informal institutions will definitely lead to better health outcomes for people with diabetes. Informal institutions, such as the ones that belong to quadrant informal - non-professionals and includes spouse and partner, family, friends, relatives, neighbours and community, are important to improve health outcomes. In a study conducted by Schiotz et al. (2011) they found that people with diabetes who had a poor functional social network were associated with lower patient activation levels, more emotional distress and less health-promoting self-management behaviours. Furthermore, Rogers et al. (2011) contend that self-management also tends to be centred on individuals' capacity and responsibility and more attention needs to be placed on contexts, resources and networks so that they can be integrated into the open systems of people's lives. Similarly August and Sorkin (2011) also argue that social network involvement reduces risk of mortality and health outcomes as social network members encourage healthy behaviours by promoting health-enhancing behaviours and also by serving as a source of influence and regulation. Within the social network, evidence suggests that spouses are the primary source of health-related social support and social control for married individuals, and in even more recent studies that focus on other cultures, other social network members that include both kin and non-kin are important in behaviour changes in cultures in which family members view the day-to-day tasks of managing a disease as a 'collaborative', rather than an independent, endeavour (August and Sorkin 2011, 712).

To suit the Indian diabetes care context, Kalra et al. (2013) propose a set of recommendations that includes: physicians encouraging patients to seek support from family members, based on individual family structures, overcome barriers in adherence to treatment and promote patterns of behaviour, which may make diabetes management easier; in weight loss programs, healthcare providers should recommend the collaboration of a spouse to actively work together to reach a common goal; and diabetes management should be made more flexible and convenient in a familial context to reinforce the patient's personal sense of health, emotional well-being and ability to maintain diabetes care. 


\section{Conclusion}

This paper acknowledges the importance of the role of both formal and informal networks, that is, they should complement each other rather than substitute one for the other. Generally, network studies focus mostly on formal networks, although definitions include both formal and informal networks. By comparing diabetes care in Australia and India, we can conclude that informal networks, such as the networks in diabetes care in India where there is a lack of presence of formal networks, play an important role. Informal networks, such as families and communities, are vital forms of support for diabetes care especially in countries with weak formal institutions of diabetes care. As diabetes care gains notoriety as one of the major disease affecting, not only Australia and India, but other parts of the world, the costs of providing diabetes care is enormous. Therefore, policy makers need to understand how networks, both formal and informal networks, work to encourage the formation of service provision and reduce the human resource burden and financial burden of the disease. It is with these financial and other costs in mind that the advantage of including informal networks provide an opportunity to reduce increased pressure on service delivery mechanisms and provisions of diabetes care. By focusing on the importance of informal institutions, to supplement the formal institutions will definitely lead to better health outcomes for people with diabetes. Through the development of a matrix of diabetes care this study stressed the importance of informal institutions, such as the ones that belong to quadrant informal - non-professionals (from Table 1) and includes spouse and partner, family, friends, relatives, neighbours and community, as important to improve health outcomes. It is anticipated that this matrix will also prove useful, not only for diabetes care, but also other policy areas where the role of non-formal institutions and networks can supplement the formal institutions and networks.

\section{References}

ADEA. www.adea.com.au.

AIHW. "Diabetes Prevalence in Australia: An Assessment of National Data Sources.". Canberra: AIHW, 2009.

Ansell, Chris, and Alison Gash. "Collaborative Governance in Theory and Practice." Journal of Public Administration Research and Theory 18, no. 4 (2007): 543-71.

August, Kristin J, and Dara H Sorkin. "Support and Influence in the Context of Diabetes Management: Do Racial/Ethnic Differences Exist?". Journal of Health Psychology 16, no. 5 (2011): 711-21.

Australia, Commonwealth of. "2010-11 Australian Government Budget--a National Health and Hospitals Network for Australia's Future." Canberra, 2010.

Aylen, T, L Watson, and R Audehm. "Nurse Specialists Co-Managing Diabetes within General Practice." European Diabetes Nursing 3, no. 1 (2006): 28-33.

Balagopal, Padmini, Thakor G Patel, N Kamalamma, and Ranjita Misra. "A Community-Based Diabetes Prevention and Management Education Program in a Rural Village in India." Diabetes Care 31, no. 6 (2008): 1097-104.

Berry, Frances S, Ralph S Brower, Sang Ok Choi, Wendy Xinfang Goa, HeeSoun Jang, Myungjung 
Kwon, and Jessica Word. "Three Traditions of Network Research: What the Public Management Research Agenda Can Learn from Other Research Communities." Public Administration Review 64, no. 5 (2004): 539-52.

Blanco, Ismael, Vivien Lowndes, and Lawrence Pratchett. "Policy Networks and Governance Networks: Towards Greater Conceptual Clarity." Political Studies Review 9 (2011): 297-308. Brinkerhoff, Jennifer M. "Government - Nonprofit Partnership: A Defining Framework." Public Administration and Development 22, no. 1 (2002): 19-30.

Carlsson, Lars. "Policy Networks as Collective Action." Policy Studies Journal 28, no. 3 (2000): 502-20.

Chow, Clara K, P Krishnam Raju, Rama Raju, K Srinath Reddy, Magnolia Cardona, David S Celermajer, and Bruce C Neal. "The Prevalence and Management of Diabetes in Rural India." Diabetes Care 29, no. 7 (2006): 1717-18.

Considine, Mark, and Jenny M Lewis. "Bureaucracy, Network, or Enterprise? Comparing Models of Governance in Australia, Britain, the Netherlands, and New Zealand." Public Administration Review 63, no. 2 (2003): 131-40.

Duit, Andreas, and Victor Galaz. "Governance and Complexity - Emerging Issues for Governance Theory." Governance: An International Journal of Policy, Administration, and Institutions 21, no. 3 (2008): 311-35.

Emerson, Kirk, Tina Nabatchi, and Stephen Balogh. "An Integrative Framework for Collaborative Governance." Journal of Public Administration Research and Theory 22, no. 1 (2012): 1-29.

Ferlie, Ewan, Louise Fitzgerald, Gerry McGivern, Sue Dopson, and Chris Bennett. "Public Policy Networks and 'Wicked Problems': A Nascent Solution?". Public Administration 89, no. 2 (2011): 307-24.

Harris, M. "Challenges in Diabetes Management." Australian Family Physician 37, no. 9 (2008): 716-20.

Hasan, Habib, Sanjay Zodpey, and Abhay Saraf. "Diabetes Care in India: Assessing the Need for Evidence-Based Education." South-East Asian Journal of Medical Education 5, no. 2 (2011): $15-18$.

Infante, F, J G Proudfoot, G P Davies, M F Harris, T K Bubner, C H Holton, and J J Beiby. "How People with Chronic Illnesses View Their Care in General Practice: A Qualitative Study." Medical Journal of Australia 181, no. 2 (2004): 70-73.

Isett, Kimberley Roussin, and Keith G Provan. "The Evolution of Dyadic Interorganizational Relationships in a Network of Publicly Funded Nonprofit Agencies." Journal of Public Administration Research and Theory 15, no. 1 (2005): 149-65.

Joshi, Shilpa, Shashank R Joshi, and Viswanathan Mohan. "Methodology and Feasibility of a Structured Education Program for Diabetes Education in India: The National Diabetes Education Program ". Indian Journal of Endocrinology and Metabolism 17, no. 3 (2013): 396-401.

Joshi, Shashank R, A K Das, V J Vijay, and V Mohan. "Challenges in Diabetes Care in India: Sheer Numbers, Lack of Awareness and Inadequate Control." Journal of the Association of Physicians of India 56 (2008): 443-50.

Kalra, Sanjay, G R Sridhar, Y P S Balhara, R K Sahay, G Bantwal, M P Baruah, M John, et al. "National Recommendations: Psychosocial Maangement of Diabetes in India." Indian Journal of Endocrinology and Metabolism 17, no. 3 (2013): 376-95.

Klijn, Erik-Hans, and Joop Koppenjan. "Governance Network Theory: Past, Present and Future." Policy \& Politics 40, no. 4 (2012): 587-606.

McGuire, Michael, and Robert Agranoff. "The Limitations of Public Management Networks." Public Administration 89, no. 2 (2011): 265-84.

Nachman, Lama, Amit Baxi, Sangeeta Bhattacharya, Vivek Darera, Piyush Deshpande, Nagaraju Kodalapura, Vincent Mageshkumar, et al. "Jog Falls: A Pervasive Healthcare Platform for 
Diabetes Management." In Proceedings of the Pervasive. 94-111, 2010.

O'Toole, Laurence J. "Treating Networks Seriously: Practical and Research-Based Agendas in Public Administration." Public Administration Review 57, no. 1 (1997): 45-52.

Osborne, Stephen P. "The New Public Governance?". Public Management Review 8, no. 3 (2006): 377-87.

Peters, B Guy, and John Pierre. "Governance without Government? Rethinking Public

Administration." Journal of Public Administration Research and Theory 8, no. 2 (1998): 22343.

Pollitt, Christopher, and Peter Hupe. "Talking About Government." Public Management Review 13, no. 5 (2011): 641-58.

Proudfoot, J, F Infante, C Holton, G Powell-Davies, T Bubner, J Beilby, and M Harris.

"Organisational Capacity and Chronic Disease Care: An Australian General Practice

Perspective." Australian Family Physician 36, no. 4 (2007): 286-88.

Provan, Keith G, and Patrick Kenis. "Modes of Network Governance: Structure, Management, and Effectiveness." Journal of Public Administration Research and Theory 18, no. 2 (2008): 22952.

Ramachandran, Ambady, Ananth Samith Shetty, Arun Nanditha, and Chamukuttan Snehalatha. "Type 2 Diabetes in India: Challenges and Possible Solutions." In Medicine Update 2013, edited The Association of Physicians of India, 2013. http://www.apiindia.org/medicine_update_2013/chap40.pdf.

Rhodes, R A W. "Policy Networks ". In The Oxford Companion to Australian Politics, edited by B Galligan and W Roberts. Oxford Reference Online: Oxford University Press, 2008.

Rogers, Anne, Ivaylo Vassilev, Caroline Sanders, Susan Kirk, Carolyn Chew-Graham, Anne Kennedy, Joanne Protheroe, et al. "Social Networks, Work and Network-Based Resources for the Management of Long-Term Conditions: A Framework and Study Protocol for Developing Self-Care Support." Implementation Science 6, no. 56 (2012): 1-7.

Saunders, M, P Schattner, and M Mathews. "Diabetes 'Cycles of Care' in General Practice - Do Government Incentives Help?". Australian Family Physician 37, no. 9 (2008): 781-84.

Schiotz, M L, M Bogelund, T Almdal, B B Jensen, and I Willaing. "Education and Psychological Aspects: Social Support and Self-Management Behaviour among Patients with Type 2 Diabetes." Diabetic Medicine 29, no. 5 (2012): 654-61.

Sorensen, Eva, and Jacob Torfing. "The Democratic Anchorage of Governance Networks." Scandinavian Political Studies 28, no. 3 (2005): 195-218.

Stoker, Gerry. "Public Value Management: A New Narrative for Networked Governance?". The American Review of Public Administration 36, no. 1 (2006): 41-57.

Taggart, J, A Schwartz, M F Harris, D Perkins, G P Davies, J Proudfoot, M Fanaian, and P Crookes. "Facilitating Teamwork in General Practice: Moving from Theory to Practice." Australian Journal of Primary Health 15, no. 1 (2009): 24-28.

Venkataraman, K, A T Kannan, and V Mohan. "Challenges in Diabetes Management with Particular Reference to India." International Journal of Diabetes in Developing Countries 29, no. 3 (2009): 103-09.

Weber, Edward P, and Anne M Khademian. "Wicked Problems, Knowledge Challenges, and Collaborative Capacity Builders in Network Settings." Public Administration Review 68, no. 2 (2007): 334-49. 